\title{
AC 2010-965: SIMCAFE: A WIKI-BASED REPOSITORY OF LEARNING MODULES FOR DEPLOYING SIMULATION TECHNOLOGY IN MECHANICAL ENGINEERING EDUCATION
}

Rajesh Bhaskaran, Cornell University 


\section{SimCafe: A Wiki-Based Repository of Learning Modules for Deploying Simulation Technology in Mechanical Engineering Education}

\section{Abstract}

Computer-based simulation technology has rapidly become a key component of mechanical engineering (ME) practice. Commerical simulation packages are used by leading companies to design, analyze and understand complex engineering systems. To help modernize the curriculum and better prepare students for their careers, an online repository of learning modules called SimCafe is being developed for deploying industrial-strength simulation software in ME education. SimCafe currently has modules for learning Finite-Element Analysis (FEA) using ANSYS and Computational Fluid Dynamics (CFD) using FLUENT. These modules are used in four courses across the ME curriculum at Cornell University. Each of these learning modules is built as a case study in applying simulation to a canonical problem. Basic modules such as flat plate boundary layer, forced convection in a pipe and plate-with-a-hole in tension connect readily with the existing undergraduate curriculum. Students compare the computational results with corresponding theory or experiments. The case studies not only teach students how to apply simulation appropriately but also simultaneously enhance the learning of engineering fundamentals through the interactive, visual interface provided by the software. SimCafe is a wiki, enabling easy collaboration among community members in developing and disseminating content for teaching simulation technology. Any registered user with appropriate privileges can create, edit and upload content to the site using his or her web browser, without the need for additional software. The site provides templates that contributors can use to create online tutorials for FEA and CFD applications. These templates structure the learning process so as to incorporate "best practices" in the use of simulation, with special emphasis on verification and validation. As students encounter the same best-practices approach repeatedly for problems across the ME curriculum, they are likely to internalize it and carry it into their careers. All SimCafe content is licensed under a Creative Commons agreement that allows free sharing and remixing for non-commercial use. At a recent university-industry workshop on the integration of simulation into engineering curricula, the idea of a central wiki-based repository of simulation learning modules was broadly endorsed. We invite community members to contribute content to SimCafe including tutorials, homework problems and quizzes so as to develop it into a comprehensive resource for ME educators.

\section{Introduction}

Computer simulation has emerged as a fundamentally new approach for solving engineering problems, one that promises to revolutionize the way engineering is conducted in the twenty-first century. Within the last fifteen years, advanced simulation has become an integral part of design, analysis and research in engineering. The increasingly widespread use of simulation has been enabled by the dramatic reduction in the cost of computing hardware and the maturing of off-the- 
shelf, commercial software packages. Driven by cost pressures, many industries are vigorously pursuing a zero-prototype future, with simulation minimizing or even replacing expensive physical prototypes. If deployed appropriately, simulation can be used to wring the most performance out of engineered systems at an acceptable cost. A vivid example of this is the case of the Speedo LZR swimsuit which was developed through a combination of simulation and physical testing. Experts used FLUENT, a commercial computational fluid dynamics (CFD) software, to design modifications in the suit that led to a reduction in the water drag on the wearer. Swimmers wearing the LZR suit went on to claim 33 of the first 36 medals in the Beijing Olympic games and continue to break world records, as reported in the popular press ${ }^{6}$. If most engineers, not just specialists with Ph.D.'s, are able to deploy simulation effectively, there would undoubtedly be significant improvements in the engineered systems affecting our everyday lives.

The skeptic would claim that the pervasive and effective use of simulation by generalist engineers is a pipedream, considering that the technology currently sees a lot of abuse from insufficiently and/or inappropriately trained users. This concern is primarily due to weaknesses in educating the average engineer about simulation, rather than due to any inherent deficiencies in the technology or the user. We hypothesize that simulation as a technology is ripe for democratization for two reasons. First, working with this technology is a visual and interactive experience, something that most people, and particularly the current generation of students, take to readily. Second, simulation enables beginners to generate solutions to practical engineering problems without the use of abstract mathematics or expensive equipment. The software takes care of the details so that the user needs to know only the essence of relevant concepts to apply the technology intelligently and effectively. For example, the user would need to understand the essential differences and relative advantages/disadvantages of first- and second-order discretization schemes, but not the fine details of these schemes and their computer implementation.

There is now widespread agreement that engineering students need to be taught the capabilities and limitations of advanced simulation at the undergraduate level, as discussed in a recent article of Mechanical Engineering magazine ${ }^{7}$. This will enable them, as practicing engineers, to apply industrial-strength simulation software to obtain useful and reliable solutions to practical engineering problems, an important skill for the modern engineering workforce. At the same time, simulation offers the opportunity to enhance learning through an interactive, visual medium and build excitement among students about engineering.

\section{Pedagogical Approach}

A university-industry workshop, ISTEC 2008, on the Integration of Simulation Technology into the Engineering Curriculum was organized in July 2008. The purpose of the workshop was to build a community of educators and practitioners collaborating on the deployment of simulation in the engineering curriculum. The event was endorsed by ASEE and drew about 90 people from 
academia and industry. At the workshop, a broad consensus emerged that there are two learning modes in simulation:

1. Learning how to use software: Students should subsequently be able to use software to solve new problems.

2. Learning fundamental concepts using software: This learning mode is especially relevant in earlier undergraduate years where it can also be used to excite students about engineering.

An important corollary is that simulation can augment rather than detract from teaching fundamental concepts that are part of the existing curriculum. Thus, instructors need not worry that introducing simulation will necessarily take away from learning of traditional concepts. In fact, it offers the opportunity to greatly enhance the learning of fundamentals as shown by many studies. For instance, Nobel laureate Carl Wieman's Physics Educational Technology group (PheT; http://phet.colorado.edu) has developed several java-based simulations for use in physics and engineering courses. Their investigations show that carefully designed simulations which allow interaction and visual display of results are more effective than lectures in helping students learn difficult concepts and unobservable phenomena in physics ${ }^{8}$. Wu and $\mathrm{Chen}^{9}$ compared student learning with just text material versus with text and MATLAB simulations. They found that students who used simulations were more motivated and performed significantly better on an achievement test. While these two studies focus on the second learning mode, our work addresses both learning modes through physics-based commercial software that have userfriendly graphical user interfaces.

There are two aspects to learning to use advanced simulation software. First, students need to develop the necessary skills to use the software interface to set up and solve a variety of engineering problems. Second, they need to understand the underlying concepts in order to apply the software correctly so as to obtain valid results. The training offered by software companies usually stresses the learning of software skills with the underlying concepts touched upon lightly, if at all. A user skilled in the intricacies of the software with a poor appreciation of the associated concepts is likely to generate grossly incorrect results. This is especially so since there are many different sources of error in a simulation: insufficient mesh resolution, incorrect boundary conditions, numerical instabilities, inappropriate application of turbulence models, and so on. Our emphasis in integrating simulations into courses is on underlying concepts rather than raw software skills. Students will be able to apply these concepts to simulate engineering systems irrespective of the specific software they are using.

The challenge facing instructors is how to balance traditional theory and numerical methods with the use of sophisticated simulation software with high upfront learning curves. A three-pronged approach is used here to overcome this challenge $e^{3,4}$. This approach involves the following elements: 
1. The simulation experience revolves around a series of case studies in applying selected software to solve canonical problems. This enables a modular approach where individual modules can be inserted into courses as deemed appropriate by the instructor.

2. Web-based tutorials are used to teach students the skills necessary to operate the software interface. This ensures that instructor time can be devoted to explaining underlying concepts rather than to teaching the intricacies of the interface.

3. The necessary numerical concepts are introduced "just-in-time" in a focused manner in order to meet tight time constraints.

\section{SimCafe}

Attendees at the ISTEC 2008 workshop felt that there was no general knowledge of what is available in terms of tutorials and other instructional resources for simulation. This has led to lots of duplication of effort and reinvention of the wheel. An index of existing curricular materials that included reviews and ratings would help to create more awareness of currently available resources for instructors. In addition, it was felt that a central internet-based repository of educational materials would be an extremely valuable resource to engineering educators. This is our motivation for developing SimCafe, a Wiki-based online resource for teaching and learning simulation.

SimCafe enables users to collaborate on developing, upgrading and maintaining simulationrelated educational materials such as tutorials. It uses an open-source model: the content works well out of the box but users can modify/adapt it. SimCafe employs a Creative Commons licensing model that allows free sharing and remixing for non-commercial use. Thus, it is envisaged that SimCafe can become a vehicle to stitch together current fragmentary efforts so as to avoid duplication and reinvention by individual instructors at different institutions. SimCafe is being developed as a community venue where instructors can share not only content but also best practices and experiences. It would also provide an index of relevant materials that includes ratings and reviews.

The core of SimCafe consists of a repository of learning modules for deploying industrialstrength simulation software in engineering education. Each of these learning modules is built as a case study in applying simulation to a canonical problem. A learning module consists of a webbased tutorial and associated homework problems. Basic modules such as flat plate boundary layer, forced convection in a pipe and plate-with-a-hole in tension connect readily with the existing undergraduate curriculum. Students compare the computational results with corresponding results from theory or lab experiments. These case studies not only teach students how to apply simulation appropriately but also simultaneously enhance the learning of engineering fundamentals through an interactive, visual medium. A case-study based organization enables a modular approach where individual modules can be inserted into existing courses as deemed appropriate by the instructor. 
SimCafe currently has modules for learning Finite-Element Analysis (FEA) using ANSYS and CFD using FLUENT. These modules are being used in four undergraduate courses in the mechanical and aerospace engineering curriculum at Cornell University. The courses cover diverse subject areas such as fluid dynamics, heat transfer, solid mechanics and numerical methods. They include required, lab-based as well as elective, lecture-based offerings. The course titles along with the software used are listed in Table 1.

\begin{tabular}{|l|l|l|l|}
\hline Course Title & Type & $\begin{array}{l}\text { Approx. } \\
\text { enrollment }\end{array}$ & Software \\
\hline $\begin{array}{l}\text { M\&AE 3272 Mechanical } \\
\text { Property \& Performance } \\
\text { Lab }\end{array}$ & Required & 120 & ANSYS 11 \\
\hline $\begin{array}{l}\text { M\&AE 4272 Fluids/Heat } \\
\text { Transfer Lab }\end{array}$ & Required & 120 & $\begin{array}{l}\text { ANSYS FLUENT 12 } \\
\text { (Workbench } \\
\text { interface) }\end{array}$ \\
\hline $\begin{array}{l}\text { M\&AE 4700/5700 Finite } \\
\text { Element Analysis }\end{array}$ & Elective & 40 & ANSYS 11 \\
\hline $\begin{array}{l}\text { M\&AE 4230/5230 } \\
\text { Intermediate Fluid } \\
\text { Dynamics }\end{array}$ & Elective & 50 & FLUENT 6.3 \\
\hline
\end{tabular}

Table 1: Mechanical and Aerospace Engineering courses at Cornell University that use SimCafe learning modules.

With the recent release of ANSYS Workbench 12, ANSYS and FLUENT have been integrated into the same interface so that FEA and CFD can be performed in the same application. The above courses are being transitioned to ANSYS Workbench so that the same interface can be used in all of them irrespective of the subject area. This will help provide a uniform learning experience in disparate courses across the mechanical and aerospace engineering curriculum. Other advantages gained by transitioning to Workbench include a more user-friendly interface, easier CAD import and automation of repetitive tasks such as parametric studies.

\section{Forced Convection Case Study}

In M\&AE 4272 Fluids/Heat Transfer Lab, we use FLUENT software to simulate a forced convection experiment. The experimental apparatus used, shown schematically in Figure 1, consists of three sections of a smooth-walled circular pipe. The first section is unheated and generates a hydrodynamically fully-developed turbulent velocity profile; the middle section is heated providing energy input to the air; and the final section is insulated providing an adiabatic mixing length to allow a single reading of the final air temperature. The apparatus is instrumented to provide measurements of mass flow rate, heat input as well as pressure and temperature at various locations. A corresponding CFD simulation for this experiment was introduced into the lab in 2003 so that students could see the experimental and CFD approaches 
side-by-side. FlowLab was the CFD software used until 2009 when it was replaced with FLUENT 12 which is integrated into the ANSYS Workbench interface.

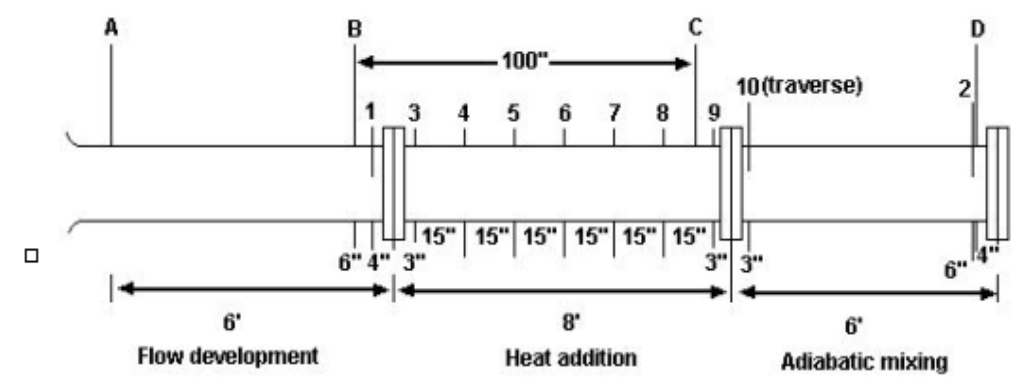

Figure 1: Schematic representation of the heated flow apparatus. A, B, C, and D are pressure taps; labels 1-10 are locations of thermocouples.

This is the first CFD experience for most students. FlowLab was originally used because it has a simplified interface that exposes only a small subset of the options in FLUENT. It was felt from experience that students at this level could not be turned loose on the full FLUENT package. The integration of FLUENT into Workbench has allowed us to use it in place of FlowLab. Students learn to perform the FLUENT simulation offline using a SimCafe tutorial. The tutorial uses nominal data; students need to repeat the calculation for their own experimental conditions which will differ from the nominal. Due to tight time constraints, cognitive load is reduced by:

- $\quad$ Making the geometry \& mesh steps optional.

- Simplifying the solve step by using the defaults which yield an adequate -- though not the most accurate -- solution.

Background information on the CFD solution process is provided through a Powerpoint presentation in the lab while students are waiting for the apparatus to reach steady state. Students learn that in the CFD simulation, FLUENT is used to solve a boundary value problem (BVP) corresponding to the experimental set-up. Thus, they see that CFD builds on BVP concepts considered in earlier Math courses. The presentation goes on to consider what the governing equations, boundary conditions and domain should be for our BVP. Students learn how to specify this BVP in the FLUENT interface offline through the SimCafe tutorial. We provide a high-level, conceptual description of discretization, iterative convergence and Reynoldsaveraging. This is justifiable since beginning users need to understand only the essence of these concepts.

In contrast to the experiment, CFD provides rich visualization capabilities which are extremely useful to develop a physical understanding of the flow. Figure 2 shows the axisymmetric temperature field in the pipe obtained from FLUENT. This plot shows how the heat added at the wall diffuses into the flow. Students can see that the flow is well-mixed at the end of the adiabatic mixing section which confirms an assumption in the experiment. Figure 3 shows the 
comparison between experiment and CFD for the temperature variation along the pipe axis. The original and refined meshes yield almost the same result. The final bulk temperature rise obtained from experiment and CFD agree well.

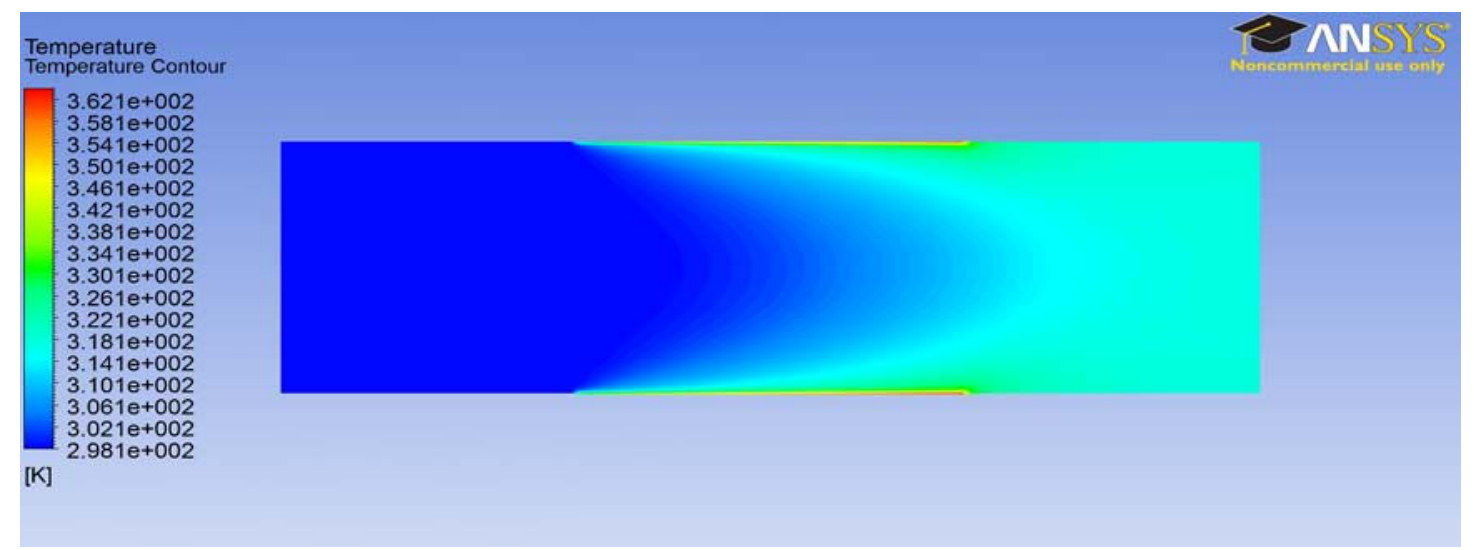

Figure 2: Temperature distribution in the pipe obtained from FLUENT.

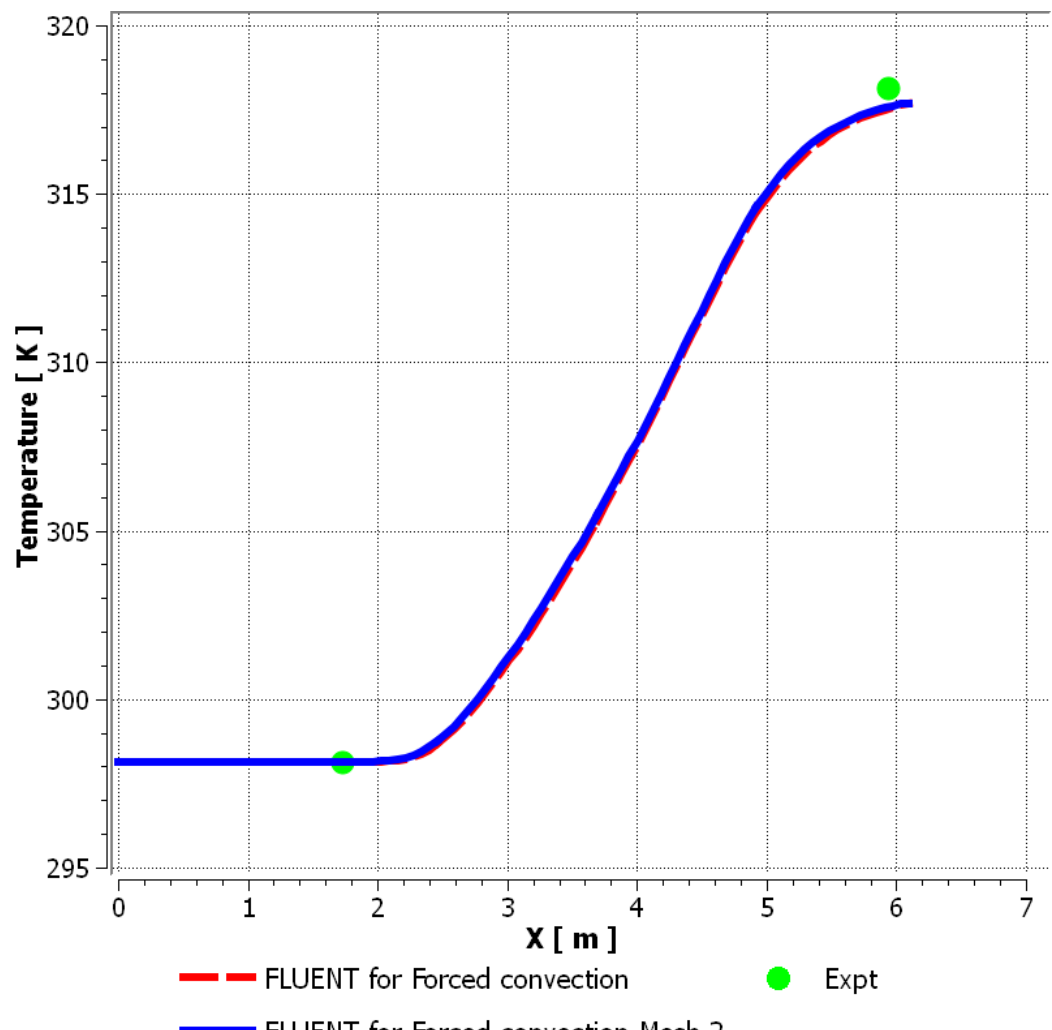

Figure 3: Temperature variation along the pipe axis obtained from CFD and experiment. 


\section{Structuring the Learning Experience}

To perform the computational case studies, students need to develop the skills to navigate the software interface which is done through web-based tutorials as in the example above. With web-based tutorials available, classroom interaction can be devoted to more value-added activities such as explaining underlying physical and numerical concepts, clearing up misconceptions, etc. As students follow the steps in a tutorial and click away with the mouse, they are apt to lose track of the big picture. After completing the tutorial, they are left with the feeling that they have followed a recipe without understanding how it needs to be modified for a different but related application.

To alleviate this problem, we provide a consistent structure to the learning experience by breaking down each set of FEA and CFD tutorials into the same collection of steps. The list of steps appears at the top of each page of the tutorial with the current step highlighted in a different color. This enables students to keep track of their progress through the solution process. By encountering the same set of steps in different tutorials, students can develop a close familiarity with it and are better equipped to apply the solution procedure to new problems. In a recent survey with 57 respondents enrolled in M\&AE 3272 Mechanical Property \& Performance Lab , more than $90 \%$ of students agreed or strongly agreed that this structure helped them understand the underlying similarity of the solution procedure for different problems. Results from this survey are discussed in more detail in Section 6.

The FEA and CFD tutorials currently use a different set of steps. These are being made the same in order to provide a uniform learning experience not only within a course but also across courses and disciplines. These steps are a superset of the steps in ANSYS Workbench 12.0 which imposes a uniform solution process across FEA and CFD applications. Figure 4 shows the steps in SimCafe and the corresponding steps in Workbench for CFD and FEA applications. As seen in the figure, SimCafe brackets the Workbench steps with a "Pre-Analysis" step at the start and a "Verification and Validation" step at the end. The latter is discussed in more detail below. The "Pre-Analysis" step addresses issues such as: "(a) What questions can the simulations answer? (b) What is the likely answer? (c) How will the results be checked?" It should be emphasized that the SimCafe steps are not ANSYS specific. Most commercial software interfaces are converging on this same high-level organization with only minor variations in the nomenclature.

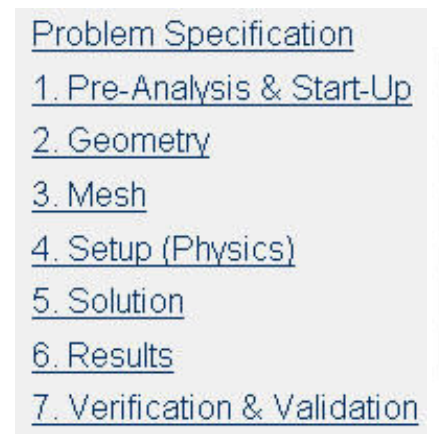

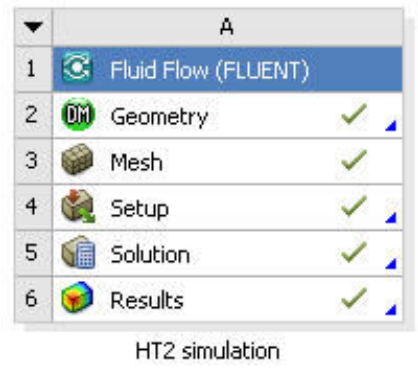

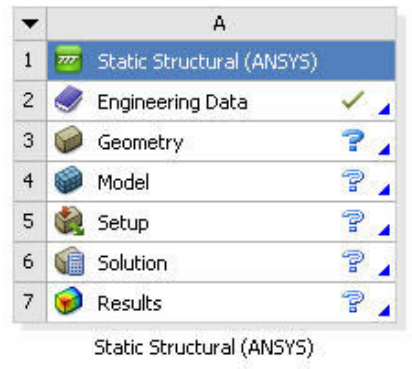


Figure 4: The list of steps used in SimCafe tutorials (left) compared with the steps in ANSYS Workbench for CFD (middle) and FEA (right) applications.

\section{Verification and Validation Step}

At the breakout sessions during the ISTEC 2008 workshop, there were many comments that can be clubbed under the rubric of Verification and Validation $(\mathrm{V} \& \mathrm{~V})$ of simulation results. Selected comments include:

- "Limitations and failures of simulations must be taught along with their successes."

- "Students should learn how to check if the result is correct."

- "Back-of-the-envelope calculations provide sanity checks."

- "V\&V should take a more prominent and consistent role in curriculum."

- "Students should learn to become critical observers."

One interpretation of these comments is that students should learn to use simulation more like experts than novices. This is related to the idea of expert versus novice thinking in the educational literature ${ }^{5}$.

To reinforce the importance of checking computational results through a formal process, the final step in every SimCafe tutorial is "Verification and Validation" as seen in Figure 4. This step considers sanity checks, mesh convergence studies, comparison with theory/experiment etc. According to AIAA's guide on $\mathrm{V} \& \mathrm{~V}$ for $\mathrm{CFD}^{1}$ :

- "Verification is the process of determining if a computational simulation accurately represents the conceptual model, but no claim is made of the relationship of the simulation to the real world."

- "Validation is the process of determining if a computational simulation represents the real world.",

In the forced convection case study discussed in section 4, verification considers the question: "Did we solve the BVP right?" At this level, students are only required to refine the mesh for this part. The validation part considers the question: "Did we solve the right BVP?" Students check this by comparing their CFD results with experiment. In the process, students generate plots similar to Figure 3. As a result, students are introduced to the concept of V\&V starting with their first CFD experience. They also encounter the V\&V step in the SimCafe modules used in the other three courses listed in Table 1. We plan to incorporate the latest V\&V thinking into the tutorials and introduce students to related standards from $\mathrm{ASME}^{2}$ and AIAA ${ }^{1}$. This concomitantly will address the ABET requirement that students be exposed to engineering standards. In the process, $\mathrm{V} \& \mathrm{~V}$ can be given a more prominent and consistent role in the curriculum. 


\section{SimCafe Templates}

We are developing templates on SimCafe which educators can use to author new web-based software tutorials that follow the structure discussed above. In the templates, each high-level step such as Verification and Validation is a separate webpage -- with the list of steps at the top and the current step highlighted in the list, as discussed earlier. Each step in the template will also include a listing of key items that need to be addressed. For instance, in the V\&V step, tutorial authors will need to address discretization and iterative convergence errors, comparisons with experiments and/or theory etc. The templates serve as a key mechanism to propagate:

- A uniform structure through all SimCafe modules irrespective of the author.

- Best practices in applying simulation.

Early adopters will be sought to evaluate and refine these templates. We already have an e-mail list of about 60 interested faculty members from the ISTEC 2008 workshop. Thus, SimCafe users are likely to encounter the same learning structure and best-practices approach for different problems across the ME curriculum. Through these repeated encounters, students have a chance to internalize best practices in their formative years and carry them into their careers.

\section{Evaluation Results}

In 2009, an 18-item survey was administered to 57 students enrolled in M\&AE 3272 Mechanical Property \& Performance Lab. The survey gathered data pertaining to user experience with the ANSYS tutorials on SimCafe looking at content, navigation, presence of technical difficulties, clarity of material, real-world applicability and overall recommendations to project team. Almost all respondents reported having completed the following three ANSYS tutorials:

1. Two-Dimensional Static Truss

2. Plate with a Hole

3. Three-Dimensional Bicycle Crank

These tutorials use 1D, 2D and 3D finite-elements, respectively. When asked about use of technology in their courses, $42 \%$ reported a preference for classes that use technology extensively, while $35 \%$ preferred classes using technology moderately.

Students reported few or no technical glitches with SimCafe and ANSYS. Table 2 summarizes the survey results on the navigational features and formatting of the tutorials. From this data and the accompanying comments, we conclude that students found the tutorials clear and easy to navigate.

\begin{tabular}{|l|c|c|c|c|c|}
\hline & $\begin{array}{c}\text { Strongly } \\
\text { Agree }\end{array}$ & Agree & Neutral & Disagree & $\begin{array}{c}\text { Strongly } \\
\text { Disagree }\end{array}$ \\
\hline $\begin{array}{l}\text { The formatting of the } \\
\text { tutorial steps (fonts, colors, }\end{array}$ & $23(40.35 \%)$ & $30(52.63 \%)$ & $4(7.02 \%)$ & $0(0.00 \%)$ & $0(0.00 \%)$ \\
\hline
\end{tabular}




\begin{tabular}{|l|l|l|l|l|l|}
\hline $\begin{array}{l}\text { etc.) made the steps easy to } \\
\text { read. }\end{array}$ & $27(47.37 \%)$ & $24(42.11 \%)$ & $6(10.53 \%)$ & $0(0.00 \%)$ & $0(0.00 \%)$ \\
\hline $\begin{array}{l}\text { I was able to move from } \\
\text { page to page without } \\
\text { getting lost or confused. }\end{array}$ & $36(63.16 \%)$ & $18(31.58 \%)$ & $2(3.51 \%)$ & $1(1.75 \%)$ & $0(0.00 \%)$ \\
\hline $\begin{array}{l}\text { The screenshots in the } \\
\text { tutorial were helpful. }\end{array}$ & $28(49.12 \%)$ & $21(36.84 \%)$ & $7(12.28 \%)$ & $1(1.75 \%)$ & $0(0.00 \%)$ \\
\hline $\begin{array}{l}\text { I was able to manage the } \\
\text { tutorial and ANSYS } \\
\text { windows simultaneously. }\end{array}$ & & & & \\
\hline
\end{tabular}

Table 2: Evaluation results on the navigational features and formatting of SimCafe tutorials.

Responses to questions on the pedagogical effectiveness of the tutorials are summarized in the table below. Students were queried about the uniform structure used in all three tutorials. 91\% either 'Agreed' or 'Strongly Agreed' (combined) that this consistency helped them to better understand the underlying similarity of the solution procedure. This suggests that a consistent learning structure across the curriculum would be beneficial to students and help them discard "recipe card" approaches in favor of more sophisticated knowledge structures and critical thinking skills. $84 \%$ of the respondents would like to see more tutorials of this type in the future.

\begin{tabular}{|l|c|c|c|c|c|c|}
\hline & $\begin{array}{c}\text { Strongly } \\
\text { Agree }\end{array}$ & Agree & Neutral & Disagree & $\begin{array}{c}\text { Strongly } \\
\text { Disagree }\end{array}$ & $\begin{array}{c}\text { Not } \\
\text { Applicable/No } \\
\text { Response }\end{array}$ \\
\hline $\begin{array}{l}\text { I understood } \\
\text { at all times } \\
\text { what the } \\
\text { tutorials were } \\
\text { asking me to } \\
\text { do. }\end{array}$ & $14(24.56 \%)$ & $30(52.63 \%)$ & $11(19.30 \%)$ & $2(3.51 \%)$ & $0(0.00 \%)$ & $0(0.00 \%)$ \\
\hline \begin{tabular}{l} 
I understood \\
at all times \\
$\begin{array}{l}\text { WHY I was } \\
\text { doing the } \\
\text { steps that I } \\
\text { was doing. }\end{array}$ \\
\hline $\begin{array}{l}\text { The tutorials } \\
\text { helped me } \\
\text { appreciate the } \\
\text { importance of } \\
\text { validating } \\
\text { computational } \\
\text { results }\end{array}$
\end{tabular} & $9(15.79 \%)$ & $30(52.63 \%)$ & $13(22.81 \%)$ & $5(8.77 \%)$ & $0(0.00 \%)$ & $0(0.00 \%)$ \\
\hline
\end{tabular}




\begin{tabular}{|l|l|l|l|l|l|l|}
\hline $\begin{array}{l}\text { The tutorials } \\
\text { enabled me to } \\
\text { see the } \\
\text { applicability } \\
\text { of FEA to the } \\
\text { real-world. }\end{array}$ & $17(29.82 \%)$ & $27(47.37 \%)$ & $10(17.54 \%)$ & $3(5.26 \%)$ & $0(0.00 \%)$ & $0 \quad(0.00 \%)$ \\
\hline $\begin{array}{l}\text { All three } \\
\text { tutorials } \\
\text { followed the } \\
\text { same nine } \\
\text { steps. This } \\
\text { structure } \\
\text { helped me } \\
\text { understand } \\
\text { the } \\
\text { underlying } \\
\text { similarity of } \\
\text { the solution } \\
\text { procedure for } \\
\text { different } \\
\text { problems }\end{array}$ & $27(47.37 \%)$ & $25(43.86 \%)$ & $4(7.02 \%)$ & $1(1.75 \%)$ & $0(0.00 \%)$ & $0 \quad(0.00 \%)$ \\
\hline $\begin{array}{l}\text { As a result of } \\
\text { the tutorials, I } \\
\text { am able to } \\
\text { apply this } \\
\text { solution } \\
\text { procedure to } \\
\text { new problems }\end{array}$ & $16(28.07 \%)$ & $31(54.39 \%)$ & $10(17.54 \%)$ & $0(0.00 \%)$ & $0(0.00 \%)$ & $0 \quad 0.00 \%)$ \\
\hline
\end{tabular}

Table 3: Evaluation results on pedagogical effectiveness of SimCafe tutorials.

Students reported that they were able to complete their FEA assignment which involved analyzing a bicycle crank design and comparing the FEA results for the crank with corresponding strain gauge measurements. Prior to the development of the online tutorials, most students were unable to complete this assignment satisfactorily. Nevertheless, many students do not comprehend why process is as important, if not more, than solutions. Student comments such as: "Too many explanations" and "Don't bother me with details" underscore the goal-focused nature of their thinking. More effort is required to convey to learners that engaging in critical thinking is the point. The message to be gotten across is that the goal is not to plug-and-chug through tutorials to get them done. Rather, it is to learn the core concepts well so that the learner can apply the solution process in the tutorials to real-world engineering problems. 


\section{Conclusion}

Remarkable recent advances in simulation technology have had a transformative effect on all aspects of engineering. It is useful to consider the limiting resource in further advances: is it computers, algorithms, models, software or people? A related question is: Which of these resources has gotten the least attention? One could argue that it is people since addressing this aspect doesn't conventionally fall under the purview of engineering R\&D programs in academia or industry. In contrast, most research universities have well-established R\&D programs that address the other limitations such as computers and algorithms. Systematic integration of advanced simulation into engineering education is a necessary condition for overcoming the people limitation.

While it is now generally recognized that engineering undergraduates need to be taught the capabilities and limitations of simulation, there is concern that the overhead of learning to use commercial packages is high preventing their integration into the curriculum. We have been able to successfully address this concern through:

1. The use of carefully-designed online learning modules to teach software skills as well as related concepts.

2. Software GUI improvements offered by ANSYS Workbench such as incorporation of FEA and CFD into a common, more intuitive interface and automation of repetitive tasks.

The SimCafe site is being developed as a Wiki-based open platform, enabling easy collaboration among community members in developing and disseminating online content for teaching simulation technology. SimCafe provides a uniform learning experience across courses so that students can see that the same high-level principles apply whether, say, solving a solid mechanics problem using FEA or a thermo-fluids problem using CFD. Verification and validation is a required step in which students check their computational results through a formal process in accordance with professional standards established by ASME and AIAA. We hypothesize that if students see the same best-practices approach repeatedly in different subject areas, they are likely to internalize it and carry it forth into their professional careers.

Since SimCafe content is licensed under a Creative Commons agreement, registered users can modify and adapt the content for educational purposes. The site also provides templates for creating FEA and CFD tutorials that follow a best-practices structure. We invite community members to contribute content to SimCafe including tutorials, homework problems and quizzes so as to develop it into a comprehensive resource for ME educators. This will help us scale up from piecemeal, institution-bound efforts to a coordinated, community-wide endeavor that would transform the curriculum. 


\section{References}

AIAA. (1998). Guide for the Verification and Validation of Computational Fluid Dynamics Simulations. Reston, VA: American Institute of Aeronautics and Astronautics.

ASME. (2006). V\&V 10 - 2006 Guide for Verification and Validation in Computational Solid Mechanics. American Society of Mechanical Engineers.

Bhaskaran, R. (2004). Integration of FEA Simulation Technology into the Undergraduate Curriculum. Proceedings of the 2004 International ANSYS Conference. ANSYS Inc.

Bhaskaran, R. (2007). Strategies for the integration of computer-based simulation technology into the engineering curriculum. Proceedings of the 2007 ASEE Annual Conference \& Exposition. Washington, DC: American Society for Engineering Education.

Bransford, J., Brown, A., \& Cocking, R. (1999). How People Learn. Washington, DC: NAS Press.

Goodgame, C. (2008, August 13). High-Tech Swimsuits: Winning Medals Too. Time .

Thilmany, J. (2008, January). In-School Analysis. Mechanical Engineering .

Wieman, C., Perkins, K., \& Adams, W. (2008). Interactive Simulations for Teaching Physics: What Works, What Doesn't, and Why. American Journal of Physics , 393-399.

Wu, W., \& Chen, W. (2008). Effect of Varied Types of Instructional Delivery Media and Messages for Engineering Education: an Experimental Study. International Journal of Engineering Education , 107-114. 